\title{
BMJ Open Association between sensory impairment and suicidal ideation and attempt: a cross-sectional analysis of nationally representative English household data
}

Maitri Khurana (D), Natalie Shoham, Claudia Cooper, Alexandra Laura Pitman (D)

To cite: Khurana M, Shoham N, Cooper C, et al. Association between sensory impairment and suicidal ideation and attempt: a cross-sectional analysis of nationally representative English household data. BMJ Open 2021;11:e043179. doi:10.1136/ bmjopen-2020-043179

- Prepublication history and additional material for this paper is available online. To view these files, please visit the journal online (http://dx.doi.org/10. 1136/bmjopen-2020-043179).

Received 27 July 2020 Revised 27 January 2021 Accepted 28 January 2021

Check for updates

(C) Author(s) (or their employer(s)) 2021. Re-use permitted under CC BY-NC. No commercial re-use. See rights and permissions. Published by BMJ.

Division of Psychiatry, UCL, London, UK

Correspondence to Dr Alexandra Laura Pitman; a.pitman@ucl.ac.uk

\section{ABSTRACT}

Objectives Sensory impairments are associated with worse mental health and poorer quality of life, but few studies have investigated whether sensory impairment is associated with suicidal behaviour in a population sample. We investigated whether visual and hearing impairments were associated with suicidal ideation and attempt.

Design National cross-sectional study.

Setting Households in England.

Participants We analysed data for 7546 household residents in England, aged 16 and over from the 2014 Adult Psychiatric Morbidity Survey.

Exposures Sensory impairment (either visual or hearing), Dual sensory impairment (visual and hearing), visual impairment, hearing impairment.

Primary outcome Suicidal ideation and suicide attempt in the past year.

Results People with visual or hearing sensory impairments had twice the odds of past-year suicidal ideation (OR 2.06; 95\% $\mathrm{Cl} 1.17$ to 2.73; $p<0.001$ ), and over three times the odds of reporting past-year suicide attempt (OR 3.12; 95\% Cl 1.57 to $6.20 ; p=0.001$ ) compared with people without these impairments. Similar results were found for hearing and visual impairments separately and co-occurring.

Conclusions We found evidence that individuals with sensory impairments are more likely to have thought about or attempted suicide in the past year than individuals without.

\section{INTRODUCTION}

Suicide is a global public health problem and a leading cause of death worldwide. ${ }^{1}$ In the UK, 6507 suicide deaths were registered in 2018, corresponding to an age-standardised suicide rate of 11.2 deaths per $100000 \mathrm{popu}$ lation. ${ }^{2}$ The causes of suicide are multifactorial and inadequately understood, although risk factors such as social deprivation, physical and mental illness, and social isolation contribute. ${ }^{3}$ Identifying further risk factors at the population level is important because it could inform the development of targeted
Strengths and limitations of this study

- Nationally representative data were used, increasing generalisability.

- The findings were adjusted for five sociodemographic and clinical covariates and were robust to sensitivity analyses simulating the biases introduced by missing data.

- Use of self-reported measures enhances disclosure of information about sensitive topics such as past suicide attempts.

- The cross-sectional nature of the data set did not allow exploration of the temporal nature of the relationship.

- Data did not include participants from some settings that could put them at higher risk for suicidal ideation and attempt (eg, inpatient units, prisons).

interventions to reduce the risk of suicide, a preventable cause of death. ${ }^{4}$

One potential contributor to suicide risk is the presence of visual or hearing impairments. Sensory impairments are associated with poorer quality of life ${ }^{56}$, greater risk of depression ${ }^{78}$ and lack of functional independence $^{9}$, which may elevate the risk of suicide above that of the general population. Poorer mental health among people with sensory impairments is seen in both older adults ${ }^{5}$ and young people. ${ }^{10}$.

One theoretical explanation for this comes from the integrated motivational-volitional model of suicidal behaviour ${ }^{11}$, which posits that triggering events (in this case, presence of visual or hearing impairment and the social and communication difficulties they bring) increase one's vulnerability to feelings of defeat/humiliation and entrapment, creating conditions for suicidal thoughts. ${ }^{11}$. Motivational factors such as a sense of thwarted belongingness and perceived 
burdensomeness could then contribute to suicidal ideation. Where other factors intervene (eg, access to means, exposure to another's suicide), this could precipitate a suicide attempt. ${ }^{11}$

Few studies have investigated the association between sensory impairments and suicidality. ${ }^{12}$ The majority of existing studies have tended to conflate hearing and visual impairments used unrepresentative samples, lacked suitable controls ${ }^{13}$, or focused solely on older adult populations ${ }^{1415}$. Although sensory impairments are more common in older people ${ }^{15}$, there is evidence to suggest that hearing impairment is becoming more prevalent in younger populations due to an increase in occupational and environmental exposure to noise ${ }^{16}$. Existing evidence regarding hearing impairment and suicidality is inconsistent, with some studies finding an association ${ }^{15} 17-19$, but others finding none. ${ }^{20}$ This may be due to samples not being representative of the wider population. Similarly, the evidence regarding the association between suicidality and visual impairment is largely inconsistent. For example, a large nationally representative Korean study found that low clarity of vision was associated with an increased risk of both suicidal attempts and ideation ${ }^{4}$, while a similar Korean study found no evidence of this association after adjustment for various covariates. ${ }^{21}$ It is important to examine the sequelae of hearing and visual impairments separately, using large general population samples, as the nature of associations may differ between groups.

Our objective was to investigate the relationship between overall sensory impairment (either visual or hearing impairment) and suicidal behaviour, that is, attempt and ideation, as well as to quantify the independent associations of hearing impairment and visual impairment with suicidal behaviour. We also tested for these associations in people with dual sensory (visual and hearing) impairment.

We hypothesised that there is an association between visual and hearing impairments and past-year suicide attempt and past-year suicidal ideation.

\section{METHODS}

We used the Strengthening the Reporting of Observational Studies in Epidemiology cross-sectional study checklist when writing our report. ${ }^{22}$

\section{Study design}

We conducted a secondary analysis of cross-sectional data from the 2014 Adult Psychiatric Morbidity Survey (APMS) ${ }^{23}$, the fourth of a series of surveys of the mental health of the general population in England. These nationally representative cross-sectional surveys are carried out every 7 years by the National Centre for Social Research and the University of Leicester. ${ }^{2324}$ They provide data on a range of mental health disorders, as well as physical health, lifestyle and sociodemographic characteristics. ${ }^{24}$
We used as our exposure variables: (1) current visual or hearing impairment, (2) dual current visual and hearing impairment (3) current visual impairment and (4) current hearing impairment, and as our outcome variables: (1) suicide attempt in the past year and (2) suicidal ideation in the past year.

\section{Sample}

The 2014 APMS sample is composed of participants aged 16 and over, living in private households in England. ${ }^{25}$ The survey used a stratified random probability sampling design. Sampling procedure and ethical review details have been previously published. ${ }^{24}$ Briefly, sampling involved two stages: sampling of Postal Sectors and then addresses within Postal Sectors. The sampling frame was the small user Postcode Address Fil, which includes delivery locations receiving fewer than 50 mail items each day, and covers most private households. From each eligible household, one adult was randomly selected to be interviewed for the first of two phases using the Kish grid method. ${ }^{26}$ This enables participants to be selected with equal probability. For phase two, a subset of the original sample underwent a structured assessment by clinically trained individuals. A total of 13313 participants were included in the sample set, and $7546(57 \%)$ usable interviews were obtained.

\section{Weighting}

We applied the original weightings provided with the APMS 2014 dataset to all analyses other than where absolute numbers are reported. The APMS weightings were designed to ensure that results are representative of the target population, by accounting for non-response and probability of selection. ${ }^{25}$ Details of the weighting process are summarised in the methods section of the APMS report. $^{25}$

\section{Accommodations for sensory impairment}

For individuals with significant visual impairment but sufficient hearing abilities, face-to-face interviews were conducted and self-completion questionnaires were read aloud by interviewers.

The APMS interviewers aimed to optimise the environment such that it was private and quiet, with loud vocalisations to support participants with hearing impairment.

\section{Exposures}

\section{Visual impairment}

We derived two independent categorical variables capturing near-vision impairment and distance vision impairment from the following interview questions respectively: 'With your glasses (or contact lenses if you wear any), do you have any difficulty seeing ordinary newsprint at arm's length?' and 'With your glasses or contact lenses if you wear any, do you have any difficulty clearly seeing the face of someone across a room, that is from $4 \mathrm{~m}$ or 12 feet away?. The participants answered these questions using a 5-point Likert-style scale: $1=$ 'no difficulty', 2 = 'mild difficulty', 3 = 'moderate difficulty', 
$4=$ 'severe difficulty' and $5=$ 'cannot do'. We combined answers to both questions to generate a binary variable representing having a visual impairment (either nearvision or distance vision, of any severity) or not.

\section{Hearing impairment}

We measured hearing impairment using responses to the question 'Do you have any difficulty hearing, or use a hearing aid?', to derive a binary yes/no variable.

\section{Sensory impairment (either)}

We combined the above hearing and visual impairment variables to create a binary variable representing having a sensory impairment of either kind.

\section{Dual sensory impairment}

We also combined hearing and visual impairment variables to create a binary variable representing having both visual and hearing impairment or not.

\section{Outcomes}

\section{Suicide attempt}

We used a binary measure of past-year suicide attempt, based on responses to the question 'Have you ever made an attempt to take your life, by taking an overdose of tablets or in some other way?', qualified by whether this had occurred in the past year.

\section{Suicidal ideation}

We used a binary measure of past-year suicidal ideation, based on responses to the question 'Have you ever thought of taking your life, even if you would not actually do it?', qualified by whether this had occurred in the past year, as above.

\section{Covariates}

We chose five covariates a priori as putative confounders: gender $^{27}$, age ${ }^{15}$, socioeconomic status ${ }^{28} 29$, ethnicity ${ }^{30} 31$ and diabetes ${ }^{32}$, measured as follows:

- Gender: self-identified at interview as male/female.

- Age range:10-year age brackets ranging from 16 to 74 .

- Area-level deprivation using the Index of Multiple Deprivation; a composite index of relative deprivation at small area level, based on seven different domains including: income; employment; education, skills and training; health and disability; access to housing and services; crime and disorders; and overall living environment. The postcode of each participant in the survey was used to link to the area of residence, which corresponded to deprivation quintiles, ranging from least to most deprived. ${ }^{25}$

- Ethnicity: participants identified their ethnicity by picking one of fifteen groups presented to them on a show card.

- Diabetes mellitus: a binary measure based on responses to the question '(Have you) ever had diabetes since age 16?'. This measure was highly collinear with hypertension.
Depression and anxiety were not adjusted for in the main analyses as they are likely to be on the causal pathway in the association between sensory impairment and suicidality.

However, as an additional post hoc analysis, we used the Revised Clinical Interview Schedule (CIS-R) to create a continuous measure describing features of minor psychiatric disorder and added this to our final models to explore whether this attenuated any associations. The CIS-R is an interviewer-administered structured interview schedule covering the presence of non-psychotic depression and anxiety symptoms (such as sleep problems, irritability and phobias). ${ }^{33}$ Results for this are presented in online supplemental table 1.

\section{Statistical analyses}

We summarised sample characteristics based on exposure status that is, sensory impairment (of either kind), compared using $\chi^{2}$ tests for categorical variables and linear regression for continuous variables.

We used multivariable logistic regression models to describe the association between each type of impairment and suicide attempt and suicidal ideation, presenting unadjusted and adjusted models for each of the exposures independently.

We used complete case analysis, such that participants with missing data on any of the variables (either hearing impairment or visual impairment, either of the two outcomes and all five covariates) were excluded from final models.

\section{Sensitivity analysis}

To assess the robustness of the findings to any biases introduced by missing data, we conducted sensitivity analyses using the best-case and worst-case scenarios to impute missing values.

For the best-case scenario, we imputed any missing values for covariates using values associated with the least risk of suicidality, that is, no diabetes ${ }^{35}$, and black or minority ethnicity. ${ }^{23}$ Where outcome values were missing we imputed zero values for suicide attempt or for suicidal ideation.

For the worst-case scenario, we imputed missing values for covariates using those associated with the greatest risk of suicidality, that is, presence of diabetes and white ethnicity. Where outcome values were missing, we imputed positive values for suicide attempt or ideation.

All analyses were conducted using Stata V.12. ${ }^{36}$

\section{Patient and public involvement \\ No patient involved.}

\section{RESULTS}

Of the 7546 individuals sampled in the 2014 APMS, $1028(12.26 \%)$ reported visual impairment (145 (1.82\%) distance visual impairment; 883 (10.43\%) near visual impairment); 1323 (14.74\%) reported hearing 
impairment; 2070 (24.13\%) reported either of these and $281(2.87 \%)$ reported dual sensory impairment. Of the 7546 , two individuals had missing data on sensory impairment, nine individuals had missing data on suicidal ideation and twelve had missing data on suicidal attempt.

\section{Participant characteristics}

A slightly higher proportion of participants reporting any sensory impairment $(52 \%, \mathrm{p}=0.002)$ or hearing impairment specifically $(56 \%, \mathrm{p}<0.001)$ were men compared with no impairment. People with sensory impairment of either type were more likely to be in the older age groups and to report white ethnicity, particularly if visually impaired. Visual impairment, but not hearing impairment, was associated with lower socioeconomic status. Participants with no sensory impairment were more likely to be single than participants with either sensory impairment. Other characteristics are summarised in table 1.

\section{Associations between sensory impairment and suicidal ideation}

We found strong evidence for an association of having a visual or hearing impairment with past-year suicidal ideation (table 2), in unadjusted (OR 1.54; 95\% CI 1.19 to $2.00 ; \mathrm{p}=0.001$ ) and adjusted OR (AOR) (AOR 2.06; 95\% CI 1.17 to 2.73 ; $\mathrm{p}<0.001)$ models. Covariates had a negative confounding effect, such that failing to account for them would have underestimated the measure of association.

Individuals with visual impairment were more likely than participants without to have had past-year suicidal ideation, in both unadjusted (OR 1.81; 95\% CI 1.36 to 2.41; $\mathrm{p}<0.001$ ) and adjusted (AOR 2.05; 95\% CI 1.51 to 2.78; $\mathrm{p}<0.001)$ models. We found no evidence for an association with hearing impairment in an unadjusted model (OR 1.26; 95\% CI 0.92 to $1.74 ; \mathrm{p}=0.146$ ), but in the adjusted model, the odds of having suicidal thoughts were almost doubled in those with hearing impairment (AOR 1.90; 95\% CI 1.34 to 2.67; $\mathrm{p}<0.001$ ).

For dual sensory impairment, we found an association with suicidal ideation in both the unadjusted and adjusted models (AOR 2.76; 95\% CI 1.67 to 4.57; $\mathrm{p}<0.001$ ).

\section{Association between sensory impairment and suicide attempt}

We found strong evidence for an association of sensory impairment (whether visual or hearing) with past-year suicide attempt (table 2). In an unadjusted model, participants with either type of sensory impairment had over three times greater odds of having attempted suicide over the past year as compared with participants without these impairments (OR 3.12; 95\% CI 1.57 to 6.20; $\mathrm{p}=0.001$ ). Following adjustment, the OR increased (AOR 5.32; 95\% CI 2.54 to $11.15 ; \mathrm{p}<0.001$ ).

Participants with visual impairment had almost five times the odds of having attempted suicide in the past year in the adjusted model (AOR 4.97; 95\% CI 2.37 to $10.41 ; \mathrm{p}<0.001)$.
For hearing impairment, there was no association with suicide attempt in an unadjusted model (OR 1.80; 95\% CI 0.78 to $4.16, \mathrm{p}=0.165)$, but following adjustment, there was evidence to support a strong association (AOR 3.58; $95 \%$ CI 1.40 to $9.16 ; \mathrm{p}=0.008$ ).

There was strong evidence that participants with dual sensory loss were significantly more likely to have attempted suicide in the past year than participants with no sensory impairment in the adjusted (AOR 6.14; 95\% CI 1.73 to 21.79; $\mathrm{p}=0.005$ ) but not unadjusted model.

In a post hoc analysis, we tested the effect of adding each putative confounder in turn (online supplemental table 2) and identified that the primary contribution to the negative confounding was that of age.

In a further post hoc analysis, we added CIS-R scores to our final models (online supplemental table 1), and found that on adjustment, most of our analysis yielded non-significant results. The only associations that remained significant were that of sensory impairment (either visual or hearing) and past-year suicide attempt and visual impairment and past-year suicide attempt.

\section{Sensitivity analyses}

Our results were relatively unchanged when imputing values reflecting best case and worst-case scenarios for missing values on covariates and outcomes (online supplemental tables 3 and 4), suggesting that the biases introduced by missing data did not influence our effect estimates.

\section{DISCUSSION}

\section{Main findings}

In our analysis of a representative household sample of adults living in England, we found an association between sensory impairment, whether visual or hearing impairment, and past-year suicide attempt and ideation. This was the case whether we combined sensory impairment types, considered each separately or co-occurring. The highest ORs were seen for participants with dual sensory impairment. We found that age was a strong negative confounder of the associations, due to the higher risk of past-year suicidality in younger age groups and elevated rates of sensory impairment in older people. Our unadjusted models, therefore, underestimated the relationship between sensory impairment and suicidality. There appeared to be evidence to support some contribution of depression and anxiety to this association, in that adding this variable to final models attenuated most of the associations. However, this would require formal testing in a longitudinal dataset.

\section{Findings in the context of other studies}

Our findings are consistent with those of previous work conducted in Korea ${ }^{14}$ describing the association between sensory impairment of either modality and suicidality, although our study was able to separate out both exposures. Our findings are also consistent with international 


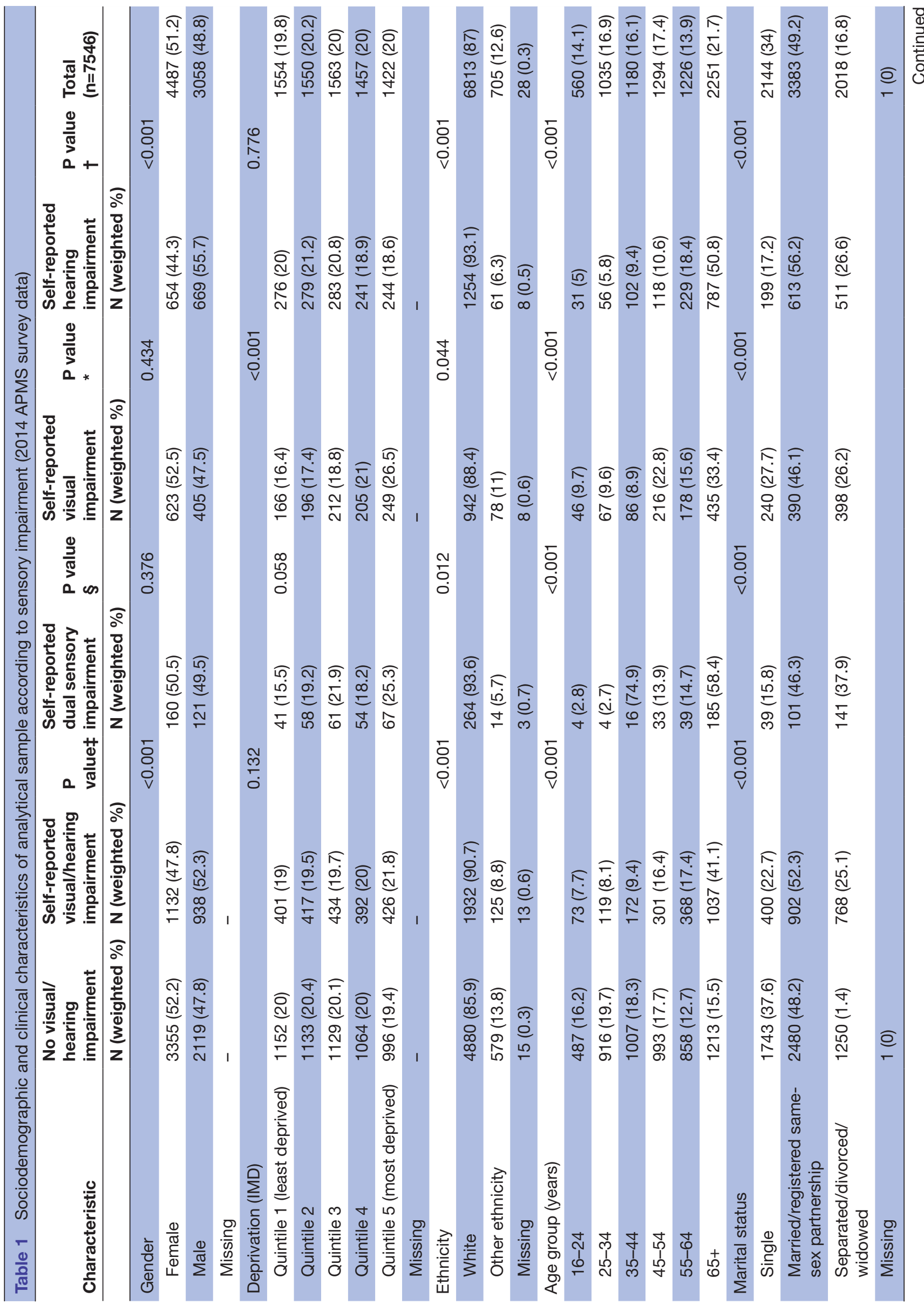




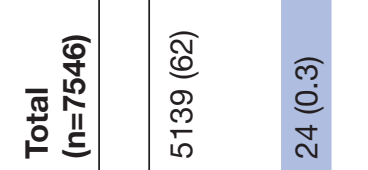

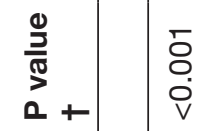

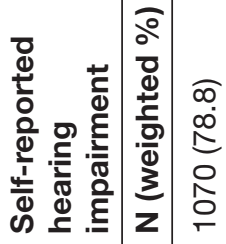

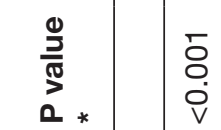

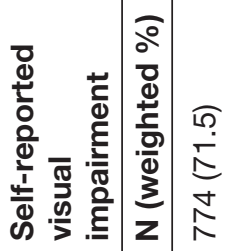

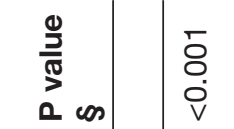

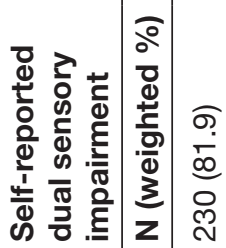

$0 \stackrel{\frac{\pi}{2}}{\frac{\pi}{2}}$

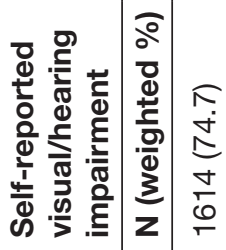

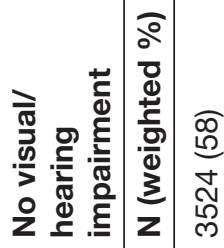

$\begin{array}{ll}5 & \overline{8} \\ \text { จ } & \end{array}$

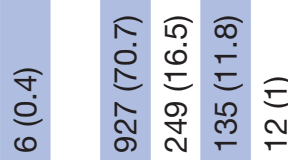

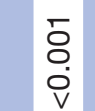

$\overline{8}$
¿

$\overline{8}$
v

ช. ฮุ

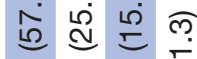

虽

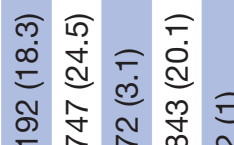

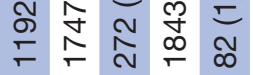

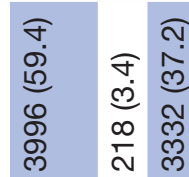

๖े $\stackrel{\substack{0 \\ 0}}{0}$

๙

त्र ल ल

๑)

के

훙

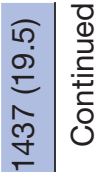

$\leftarrow$

空

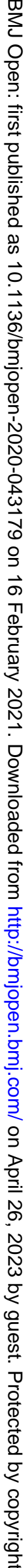

$\overrightarrow{0}$

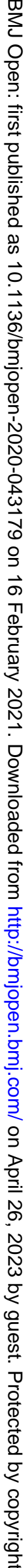

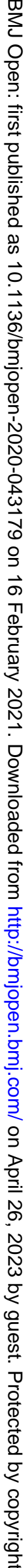

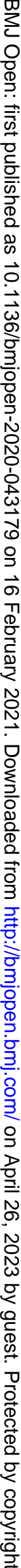

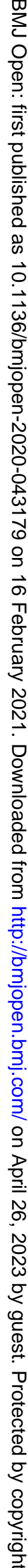

$\vec{\sigma}$

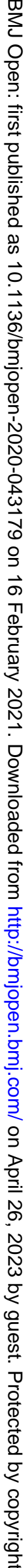

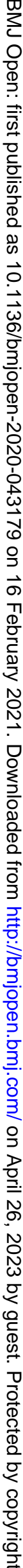

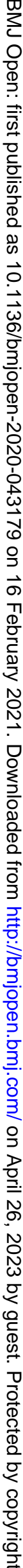

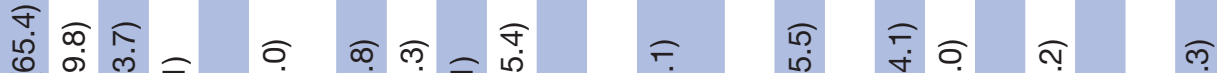

ก)

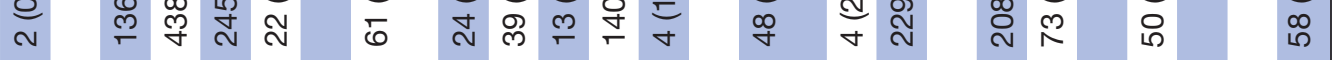<smiles>[SiH3]C[SiH3]</smiles>

$\overline{8}$
$\dot{0}$
$\mathrm{v}$

চे

$\overline{8}$
Q

§ิ

बं का

10.

芒 突

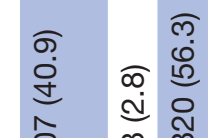

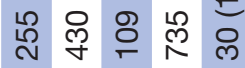

हิ

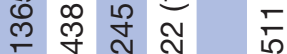

穴

ผ

ले

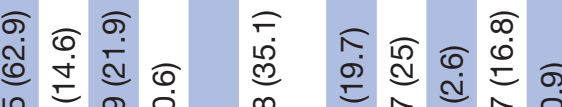

อ

文

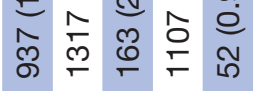

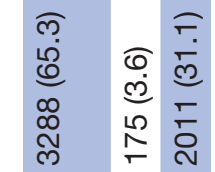

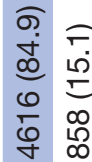

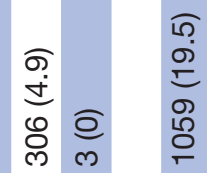

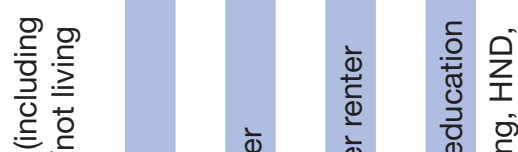

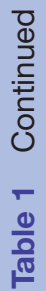

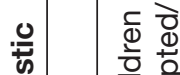

蒙

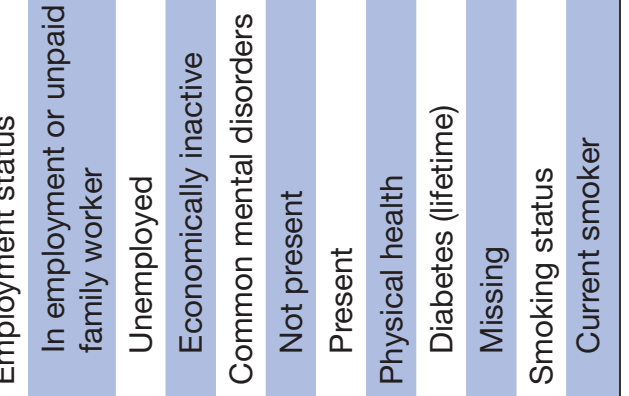



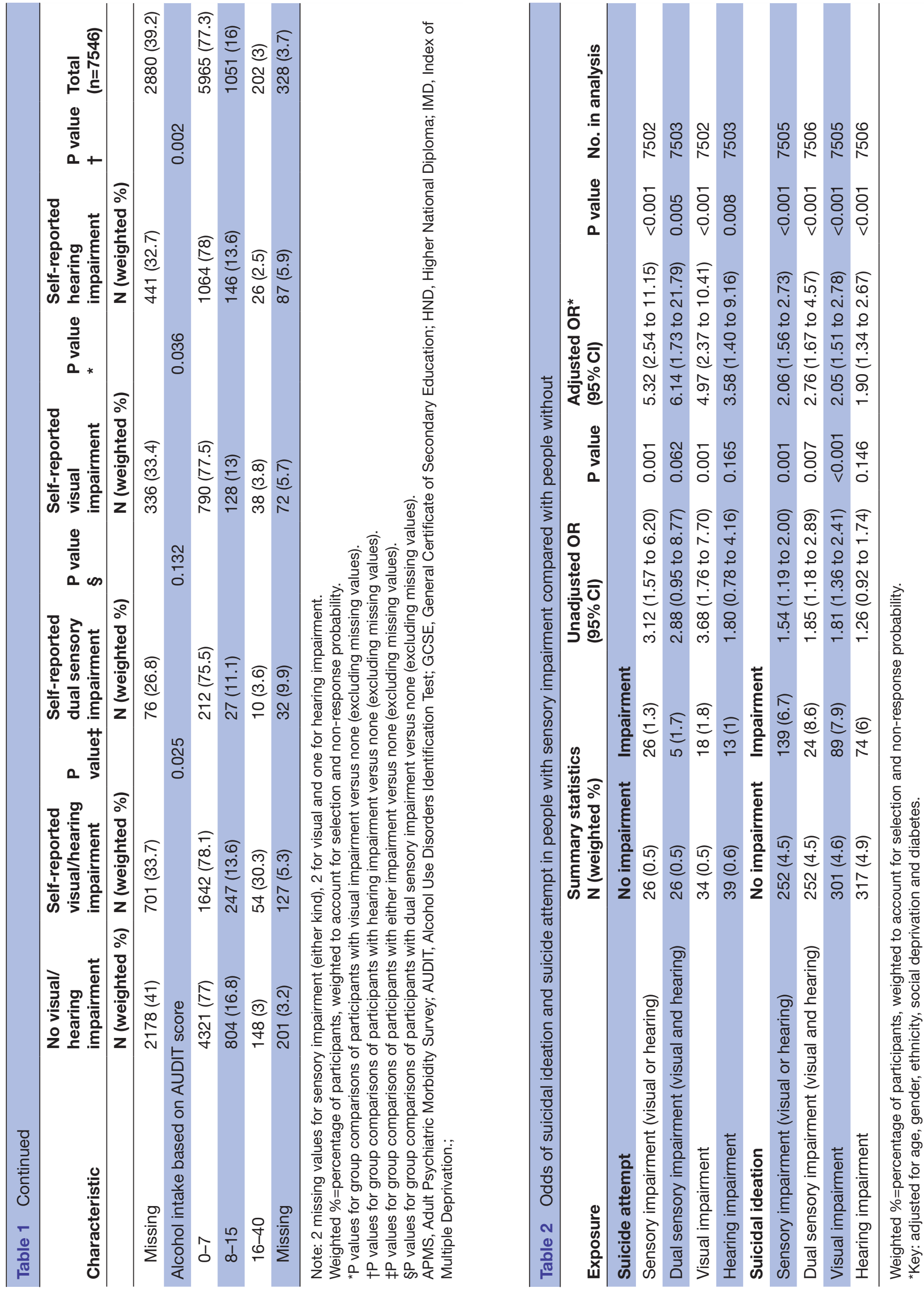

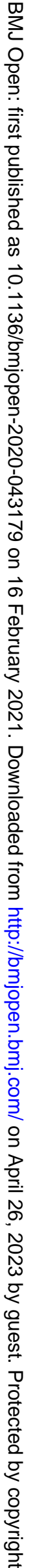


work finding an association between hearing impairment and suicidality, although this did not address visual impairment. ${ }^{13}$ They are also consistent with a large nationally representative Korean study where researchers found low clarity of vision to be associated with an increased risk of both suicidal attempt and ideation. ${ }^{4}$ However, our findings conflict with those of another nationally representative Korean study finding no association of visual impairment with suicidal ideation following adjustment of sociodemographic characteristics and restriction of daily activities. ${ }^{21}$ Authors of this paper suggested that visual impairment may only be associated with suicide indirectly through its effect of restricting daily activities. This reflects findings of a nationwide Finnish study where visual impairment was associated with suicide indirectly through its effect on health. ${ }^{37}$ Restriction in daily activities or self-rated health was not considered in the current study.

Our results regarding hearing impairment are consistent with studies that found an association between hearing impairment and suicide in specific populations such as $\mathrm{D} /$ deaf children ${ }^{19} \mathrm{D} /$ deaf adults ${ }^{18}$, older adults $^{14}$,and people with co-occurring substance abuse. ${ }^{38}$ However, our results contradict findings of another study where risk of suicide was similar in hearing and nonhearing individuals. ${ }^{20}$ The suicide outcome used in this study was however a composite measure of 'risk to self' rather than completed suicide.

Finally, our analyses of co-occurring impairments are also consistent with the previously mentioned large Korean study which found that people with dual sensory impairment had a greater a risk of suicidality. ${ }^{14}$ This study, similar to ours, also found the highest risk in individuals with dual impairment.

\section{Strengths and limitations}

The present study contributes to the limited literature assessing the association between sensory impairment and suicide in the general population. Its greatest strength is the use of a nationally representative population sample and our ability to test associations with different combinations of sensory impairment. Findings were adjusted for five predetermined sociodemographic and clinical covariates and were robust to sensitivity analyses simulating the biases introduced by missing data.

We also acknowledge limitations. The cross-sectional nature of our data meant that we could not explore the temporal nature of the relationship. Our measure of sensory impairment in the last 12 months meant we could establish recency of impairment but not onset. The possibility of reverse causation cannot be ruled out, particularly as past suicide attempts are a risk factor for repeat suicide attempts. ${ }^{39}$ Furthermore, we were unable to investigate the long-term effect of sensory impairment on suicidality, the influence of time spent in a state of sensory impairment and the effect of different causes of impairment on suicidality. For example, previous research has found life satisfaction to be higher when an impairment is congenital rather than acquired later in life. ${ }^{40}$ Qualitative work could provide insights into the attitudes of people with sensory impairment towards any restrictions to their social functioning, particularly in relation to loneliness, stigma and a sense of entrapment and suicidality.

Further, despite the efforts made by APMS researchers to ensure that this was a nationally representative household survey, we acknowledge the potential for selection bias that may have affected our results. Examples of this may include participants with hearing impairment not hearing a knock on the door. The APMS sampling is also restricted to individuals from private households and therefore excludes individuals from institutional settings such as prisons, inpatient units and children's homes, who constitute approximately $2 \%$ of the population. ${ }^{23}$ These groups may have higher rates of suicidal behaviour, ${ }^{41}$ and poorer mental health. ${ }^{23}$ Given the older age profile of people in residential care and the association of sensory impairment with older age, omission of institutional settings may have led to an underestimate of the associations. Additionally, the APMS survey may have excluded people who are unable to live independently in private households due to their impairments, which may have resulted in exclusion of people with the highest degree of impairment. Further, with regards to hearing impairment, the lack of sign translation suggests that the survey missed people with congenital d/Deafness. ${ }^{42}$

Another potential limitation regarding hearing impairments is that our measure of hearing impairment included participants using a hearing aid, regardless of whether their hearing was corrected while using it. This suggests that we may have included individuals without current hearing issues. However, we chose to be inclusive in this definition because of evidence describing the perceived ineffectiveness, discomfort and stigma of hearing aid use. ${ }^{43-45}$

We also acknowledge the potential for non-response bias. For example, it is likely that individuals with severe impairment may not have felt comfortable letting a researcher into their home, and those feeling suicidal may not have had the motivation to engage with a research interview.

Finally, both sensory impairment and suicidal behaviour were measured using self-reported measures. These are inherently subjective and susceptible to both recall and social desirability bias, which may have led to under-reporting. ${ }^{46}$ Nevertheless, APMS interviewers used computer-assisted self-interviewing, and this is likely to have enhanced disclosure of such information through a reduction in social desirability bias. ${ }^{25}$ However, with regard to the use of self-reported measures, it is important to note that the APMS survey did make specific accommodations for participants with sensory impairments some of which may have resulted in under-reporting of outcomes related to suicidality. For example, where visual impairments indicated this, self-completion questionnaires were read out to participants. This may have led to under-reporting of outcomes related to suicide due to social desirability bias. 


\section{Clinical implications}

The strong association identified between sensory impairment and suicidal ideation and attempt highlights the importance of considering this population in the assessment of suicide risk and prevention. Since both of these impairments can cause communication difficulties, access to mental healthcare may be limited as compared with the general population. This study suggests a need for targeted assessment and intervention in this population, as well as a strong rationale for optimising visual or hearing function. Professionals such as general practitioners, ophthalmologists and otolaryngologists are well placed to notice the signs and symptoms of suicidality in the context of sensory impairment, and promote referral of at-risk individuals for mental healthcare. The same applies to community audiology services and commercial opticians, where training in suicide awareness may help practitioners to feel more confident in handling situations where there are concerns about a client.

Further research is needed to understand the mediators of suicide risk in individuals with sensory impairment, of which loneliness is one candidate. Loneliness is known to be a problem in people with sensory impairment ${ }^{40} 4748$ and previous work using AMPS and other datasets has described an association between loneliness and suicidality. ${ }^{49-52}$ Impairments in communication might cause people with sensory impairment to feel lonely, even if they have objective social support. ${ }^{5354}$ In qualitative work, individuals with hearing loss report feelings of profound loneliness due to the difficulties they experience in interacting with others around them. ${ }^{55}$ The stigma of disability is another potential candidate mediator, and further work is needed to explore how public stigma and selfstigma influence suicidality. Other factors such as locus of control, self-perception and self-esteem are particularly relevant to both visual and hearing impairment ${ }^{56-58}$ and may be potential mediators in this relationship. There is a clear need for further longitudinal studies to gain a better understanding of the pathways to suicidality in people with sensory impairment, so that we can develop and evaluate appropriate interventions.

\section{CONCLUSION}

Our findings provide strong evidence to support a crosssectional association between sensory impairments and suicide attempt and ideation. In view of the cross-sectional nature of the data, further longitudinal research is warranted to explore the temporal relationship between sensory impairment and suicidality and the contribution of potential mediators.

Twitter Maitri Khurana @khuranamaitri and Alexandra Laura Pitman @DrAPitman

Acknowledgements We acknowledge everyone who participated in the APMS surveys or conducted interviews for NatCen. Permission to analyse the 2014 APMS dataset to investigate mental health outcomes in LGB groups was given by NHS Digital in 2019 (DARS reference number DARS-NIC-164594-K4C5N-V.2.6, 10.5.19).

Contributors Study hypothesis conceived by ALP, NS and CC. Statistical analysis plan devised by ALP, NS and MK. Analysis conducted by MK with input from ALP, NS and CC. Literature search conducted by MK. Manuscript drafted by MK with input from ALP, NS and CC.All authors contributed to revisions. All authors met the criteria for authorship and no conflicts of interest were found.

Funding This research received no specific grant from any funding agency, commercial or not-for-profit sectors. ALP, NS and CC are supported by the National Institute for Health Research (NIHR) University College London Hospitals (UCLH) Biomedical Research Centre (BRC).

Competing interests None declared.

Patient consent for publication Not required.

Ethics approval Ethical approval for APMS 2014 was obtained from the West London National Research Ethics Committee (reference number 14/L0/0411). Ethical approval was not required for secondary analysis, since the data were anonymised.

Provenance and peer review Not commissioned; externally peer reviewed.

Data availability statement Data may be obtained from a third party and are not publicly available. The data that support the results obtained from this study are available from NHS Digital. Restrictions apply to the availability of these data.

Supplemental material This content has been supplied by the author(s). It has not been vetted by BMJ Publishing Group Limited (BMJ) and may not have been peer-reviewed. Any opinions or recommendations discussed are solely those of the author(s) and are not endorsed by BMJ. BMJ disclaims all liability and responsibility arising from any reliance placed on the content. Where the content includes any translated material, BMJ does not warrant the accuracy and reliability of the translations (including but not limited to local regulations, clinical guidelines, terminology, drug names and drug dosages), and is not responsible for any error and/or omissions arising from translation and adaptation or otherwise.

Open access This is an open access article distributed in accordance with the Creative Commons Attribution Non Commercial (CC BY-NC 4.0) license, which permits others to distribute, remix, adapt, build upon this work non-commercially, and license their derivative works on different terms, provided the original work is properly cited, appropriate credit is given, any changes made indicated, and the use is non-commercial. See: http://creativecommons.org/licenses/by-nc/4.0/.

\section{ORCID iDs}

Maitri Khurana http://orcid.org/0000-0002-8110-616X

Alexandra Laura Pitman http://orcid.org/0000-0002-9742-1359

\section{REFERENCES}

1 Synnott J, loannou M, Coyne A, et al. A content analysis of online suicide notes: attempted suicide versus attempt resulting in suicide. Suicide Life Threat Behav 2018;48:767-78.

2 Manders B. Suicides in the UK: 2017 registrations, 2018. Available: https://www.ons.gov.uk/peoplepopulationandcommunity/birthsde athsandmarriages/deaths/bulletins/suicidesintheunitedkingdom/ 2017registrations [Accessed 26 Jan 2020].

3 Batty GD, Kivimäki M, Bell S, et al. Psychosocial characteristics as potential predictors of suicide in adults: an overview of the evidence with new results from prospective cohort studies. Transl Psychiatry 2018;8:22.

$4 \mathrm{Rim} \mathrm{TH}$, Lee CS, Lee SC, et al. Influence of visual acuity on suicidal ideation, suicide attempts and depression in South Korea. $\mathrm{Br} J$ Ophthalmol 2015;99:1112-9.

5 Eisele M, Kaduszkiewicz H, König H-H, Lange C, Scherer M, et al. Determinants of health-related quality of life in older primary care patients: results of the longitudinal observational AgeCoDe study. $\mathrm{Br}$ $J$ Gen Pract 2015;65:e716-23.

6 Fischer ME, Cruickshanks KJ, Klein BEK, et al. Multiple sensory impairment and quality of life. Ophthalmic Epidemiol 2009;16:346-53.

7 Rovner BW, Ganguli M. Depression and disability associated with impaired vision: the movies project. J Am Geriatr Soc 1998;46:617-9.

8 Li C-M, Zhang X, Hoffman HJ, et al. Hearing impairment associated with depression in US adults, National health and nutrition examination survey 2005-2010. JAMA Otolaryngol Head Neck Surg 2014;140:293-302.

9 Raina $\mathrm{P}$, Wong $\mathrm{M}$, Massfeller $\mathrm{H}$. The relationship between sensory impairment and functional independence among elderly. BMC Geriatr 2004;4:3.

10 Moses T. Suicide attempts among adolescents with self-reported disabilities. Child Psychiatry Hum Dev 2018;49:420-33. 
11 O'Connor RC, Kirtley OJ. The integrated motivational-volitional model of suicidal behaviour. Philos Trans $R$ Soc Lond B Biol Sci 2018;32:295-8

12 Meyer-Rochow VB, Hakko H, Ojamo M, et al. Suicides in visually impaired persons: a nation-wide register-linked study from Finland based on thirty years of data. PLoS One 2015;10:e0141583.

13 Turner O, Windfuhr K, Kapur N. Suicide in deaf populations: literature review. Ann Gen Psychiatry 2007;6:26.

$14 \mathrm{Kim}$ Y, Kwak Y, Kim J-S. The association between suicide ideation and sensory impairment among elderly Koreans. Aging Ment Health 2015;19:658-65.

15 Cosh S, Carrière I, Daien V, et al. Sensory loss and suicide ideation in older adults: findings from the Three-City cohort study. Int Psychogeriatr 2019;31:139-145.

16 Wallhagen MI, Strawbridge WJ, Cohen RD, et al. An increasing prevalence of hearing impairment and associated risk factors over three decades of the Alameda County study. Am J Public Health 1997;87:440-2.

17 Landsberger SA, Diaz DR, Spring NZ, et al. Psychiatric diagnoses and psychosocial needs of outpatient deaf children and adolescents. Child Psychiatry Hum Dev 2014;45:42-51.

18 Sheppard K, Badger T. The lived experience of depression among culturally deaf adults. J Psychiatr Ment Health Nurs 2010;17:783-9.

19 Embree JA. Age of language acquisition and PrAge of language acquisition and prevalence of suicidal Behaevalence of suicida behavior vior in a deaf pin a deaf population with co-occurring substance use Disoropulation with co-occurring substance use disorder Der, 2017. Available: https://repository.wcsu.edu/cgi/ viewcontent.cgi?article $=1029 \&$ context $=$ jadara

20 Coll KM, Cutler MM, Thobro P, et al. An exploratory study of psychosocial risk behaviors of adolescents who are deaf or hard of hearing: comparisons and recommendations. Am Ann Deaf 2009;154:30-5.

21 Cho GE, Lim DH, Baek M, et al. Visual impairment of Korean population: prevalence and impact on mental health. Invest Ophthalmol Vis Sci 2015;56:4375-81.

22 von Elm E, Altman DG, Egger M, et al. Strengthening the reporting of observational studies in epidemiology (STROBE) statement: guidelines for reporting observational studies. BMJ 2007;335:806-8.

23 Mcmanus S, Bebbington P, Jenkins R. Mental health and wellbeing in England: adult psychiatric morbidity survey 2014. 2016. England: NHS digital, 2016

24 McManus S, Bebbington PE, Jenkins R, et al. Data resource profile: adult psychiatric morbidity survey (APMS). Int J Epidemiol 2020;49:361-2.

25 Byron C, Morgan Z, Bridges S, et al. 'Chapter 14: Methods' in McManus S, Bebbington P, Jenkins R, Brugha T. (eds) Mental health and wellbeing in England: Adult Psychiatric Morbidity Survey 2014. Leeds: NHS Digital, 2016.

26 Kish L. Sampling organizations and groups of unequal sizes. Am Sociol Rev 1965;30:564-72 https://www.ncbi.nlm.nih.gov/pubmed/ 14325826

27 Abou-Gareeb I, Lewallen S, Bassett K, et al. Gender and blindness: a meta-analysis of population-based prevalence surveys. Ophthalmic Epidemiol 2001;8:39-56.

28 Scholes S, Biddulph J, Davis A, et al. Socioeconomic differences in hearing among middle-aged and older adults: cross-sectional analyses using the health survey for England. BMJ Open 2018;8:e019615-10.

29 Yip JLY, Luben R, Hayat S, et al. Area deprivation, individual socioeconomic status and low vision in the EPIC-Norfolk eye study. $J$ Epidemiol Community Health 2014;68:204-10.

30 Sivaprasad S, Gupta B, Gulliford MC, et al. Ethnic variation in the prevalence of visual impairment in people attending diabetic retinopathy screening in the United Kingdom (drive UK). PLoS One 2012;7:e39608-8.

31 Dawes $\mathrm{P}$, Fortnum H, Moore DR, et al. Hearing in middle age. Ear Hear 2014;35:e44-51.

32 Khan A, Petropoulos IN, Ponirakis G, et al. Visual complications in diabetes mellitus: beyond retinopathy. Diabet Med 2017;34:478-84

33 Lewis G, Pelosi AJ, Araya R, et al. Measuring psychiatric disorder in the community: a standardized assessment for use by lay interviewers. Psychol Med 1992;22:465-86.
34 Stochl J, Croudace T. Mokken scaling analysis of revised clinical interview schedule (CIS-R) psychiatric status rating scales in a nationally representative sample: the 2007 adult psychiatric morbidity survey of England. J Addict Med Therapy 2013;2:1005.

35 Elamoshy R, Bird Y, Thorpe L, et al. Risk of depression and suicidality among diabetic patients: a systematic review and meta-analysis. $J$ Clin Med 2018;7. doi:10.3390/jcm7110445. [Epub ahead of print: 16 11 2018].

36 StataCorp LP. Stata statistical software: release 12. College Station, TX: StataCorp LP, 2011: 2011.

37 Lam BL. Reported visual impairment and risk of suicide. Arch Ophthal 2008;126:975

38 Embree JA, Wilson JF, Fraker S. Prevalence of suicide attempts in a deaf population with co-occurring substance use disorder. JADARA 2012;45:258-72.

39 Bilsen J. Suicide and youth: risk factors. Front Psychiatry 2018;9:1-5.

40 Hadidi MS, Al Khateeb JM. Loneliness among students with blindness and sighted students in Jordan: a brief report. International Journal of Disability, Development and Education 2013;60:167-72

41 Fazel S, Ramesh T, Hawton K. Suicide in prisons: an international study of prevalence and contributory factors. Lancet Psychiatry 2017;4:946-52.

42 British Deaf Association. What is deaf culture? 2015. Available: https://bda.org.uk/what-is-deaf-culture/

43 Barker AB, Leighton P, Ferguson MA. Coping together with hearing loss: a qualitative meta-synthesis of the psychosocial experiences of people with hearing loss and their communication partners. Int $J$ Audiol 2017;56:297-305

44 McCormack A, Fortnum $\mathrm{H}$. Why do people fitted with hearing AIDS not wear them? Int J Audiol 2013;52:360-8.

45 Arrowsmith L. Hidden disadvantage: why people with hearing loss are still losing out at work. London: Action on Hearing Loss, 2014.

46 Haberer JE, Trabin T, Klinkman M. Furthering the reliable and valid measurement of mental health screening, diagnoses, treatment and outcomes through health information technology. Gen Hosp Psychiatry 2013;35:349-53.

47 Sung Y-K, Li L, Blake C, et al. Association of hearing loss and loneliness in older adults. J Aging Health 2016;28:979-94.

48 Ge S, Pan W, Wu B, et al. Longitudinal interrelationship between sensory loss, social support, loneliness, and cognition. Innovation in Aging 2019;3:S818.

49 Schinka KC, Van Dulmen MHM, Bossarte R, et al. Association between loneliness and suicidality during middle childhood and adolescence: longitudinal effects and the role of demographic characteristics. J Psychol 2012;146:105-18.

50 Tan L, Xia T, Reece C. Social and individual risk factors for suicide ideation among Chinese children and adolescents: a multilevel analysis. Int J Psychol 2018;53:117-25.

51 Stickley A, Koyanagi A, Loneliness KA. Loneliness, common mental disorders and suicidal behavior: findings from a general population survey. J Affect Disord 2016;197:81-7.

52 Stravynski A, Boyer $R$. Loneliness in relation to suicide ideation and parasuicide: a population-wide study. Suicide Life Threat Behav 2001;31:32-40

53 Khazem LR, Jahn DR, Cukrowicz KC, et al. Physical disability and the interpersonal theory of suicide. Death Stud 2015;39:641-6.

54 Chu C, Rogers ML, Gai A, et al. Role of thwarted Belongingness and perceived Burdensomeness in the relationship between violent Daydreaming and suicidal ideation in two adult samples. $J$ Aggress Confl Peace Res 2017;10:11-23.

55 Sheppard K. Deaf adults and health care: giving voice to their stories J Am Assoc Nurse Pract 2014;26:504-10.

56 AWN R, MacKay GF. Self-Perception and locus of control in visually impaired college students with different types of vision loss. J Vis Impair Blind 2002;96:254-66.

57 Papadopoulos K, Paralikas T, Barouti M, et al. Self-Esteem, locus of control and various aspects of psychopathology of adults with visual impairments. International Journal of Disability, Development and Education 2014;61:403-15.

58 Luckner JL. Altering locus of control of individuals with hearing impairments by outdoor-adventure courses. J Rehabil 1989;55:62. 